\title{
Could current factors be associated with retrospective sports injuries in Brazilian jiu-jitsu? A cross-sectional study
}

Dayana das Graças ${ }^{1,4}$, Letícia Nakamura ${ }^{2,4}$, Fernando Sérgio Silva Barbosa ${ }^{1,4}$, Paula Felippe Martinez ${ }^{1,2,4}$, Filipe Abdalla Reis ${ }^{3}$ and Silvio Assis de Oliveira-Junior ${ }^{1,2,4^{*}}$

\begin{abstract}
Background: Brazilian jiu-jitsu is characterized by musculoskeletal disorders and high occurrence of sports injuries. The present study was aimed to analyze some internal factors, as well as to describe occurrence and characteristics of retrospective musculoskeletal injuries in different age groups of Brazilian jiu-jitsu practitioners.

Methods: One hundred ninety-three Brazilian jiu-jitsu practitioners, which were divided into three age groups: Adolescent, Adult, and Master. Besides anthropometric characterization, standard clinical tests were conducted to analyze the global and segmental joint flexibility, lumbar spine range of motion, and handgrip strength. Sports injury occurrence and total physical activity were obtained from an adapted morbidity survey and International Physical Activity Questionnaire - Short Form (IPAQ-SF), respectively.

Results: A total of 247 cases of retrospective injuries was registered (1.27 injury/ participant). Occurrence of rectus femoral muscle retraction in the right leg was increased within Master. Adult and Master have exhibited higher occurrence of sports injuries than Adolescent group $(p<0.05)$. Joint injuries were the most common sports-related injuries by all Brazilian jiu-jitsu practitioners. While female gender and exposure time constituted the most predictive variables for sports injury occurrence in Adolescent, graduation level was more associated with sports injuries occurrence in Adult.

Conclusions: Joint injuries derived from combat demands were the main sports injury in all age categories of Brazilian jiu-jitsu. Master subjects presented a higher occurrence of clinical changes and retrospective musculoskeletal injuries in relation to other age groups. Female gender and exposure time constituted the main predictive factors in adolescent subjects, while graduation category was more directly associated with retrospective injury onset in the Adult group.
\end{abstract}

Keywords: Epidemiology, Athletic performance, Athletic injuries, Sports medicine

\section{Background}

Brazilian jiu-jitsu is a self-defense sport based on the principle of defeating the adversary: subjugating them by using their own strength [1]. As a strategic sport, Brazilian jiu-jitsu is a high-intensity combat sport, combining intermittent bouts of very intense anaerobic exercise, interspersed with lower-intensity periods of aerobic activities

\footnotetext{
*Correspondence: oliveirajr.ufms@gmail.com

${ }^{1}$ Postgraduate Program in Health and Development, Federal University of

Mato Grosso do Sul, Campo Grande, MS, Brazil

${ }^{2}$ School of Physical Therapy, Federal University of Mato Grosso do Sul,

Campo Grande, MS, Brazil

Full list of author information is available at the end of the article
}

[2-5]. It requires concentration, balance and important physical conditioning to execute takedowns, sweeps, joint locks and chokes in different circumstances of body combat [1-5].

These different requisites of Brazilian jiu-jitsu, as well as high sport competitiveness, excessive training intensity, and differences between stress and recovery have constituted external risk factors for the onset of musculoskeletal injuries in fighters [6-9]. Also, age, body composition, previous history of sports injuries, posture, and muscle flexibility are important internal characteristics, which have been associated with the occurrence of new 
injuries $[1,6,9]$. From this pathophysiological perspective, a complete understanding of the potential causes of sports injury needs to address the multifactorial nature of musculoskeletal injuries in any sport modality [6].

In this context, possible associations among different characteristics and musculoskeletal injuries occurrence have been continuously reported in many sport modalities, such as track and field [10], volleyball [11], soccer [12], and judo [13]. However, regarding Brazilian jiujitsu, relationships among different external and internal features with respect to the injuries occurrence still need to be clarified. It is noteworthy that the investigation of clinical predisposing factors and characterization of sports injuries are of great prophylactic potential [1].

Since different internal characteristics may be progressively affected by the age step $[6,14]$, the present study aimed to analyze some internal elements, such as flexibility, training exposure and anthropometric measures, as well as to describe occurrence and characteristics of retrospective musculoskeletal injuries in different age groups of Brazilian jiu-jitsu practitioners. Although these parameters have not been clarified in previous studies with respect to Brazilian jiu-jitsu practitioners, our initial hypothesis is that master practitioners, i.e. 30-year old practitioners or older, present more significant clinical disorders and increased occurrence of musculoskeletal injuries, when compared to younger participants. Based on different circumstances of combat [1-5], joint injuries in upper limbs are the main type of injury in all age group of Brazilian jiu-jitsu fighters.

\section{Methods}

\section{Ethical approval and consent to participate}

The protocol was approved by the local ethics committee (Protocol 575.773/ 2014; CAAE 26804614.7.0000.0021), and all participants were given verbal and written information before they agreed to participate and to sign a consent form. Parental or legal guardian consent, written and verbal, was obtained for all participants under the age of 18 years-old.

\section{Participants}

This cross-sectional study was performed at the Laboratory of Striated Muscle Study (LEME/ CEI) Federal University of Mato Grosso do Sul, Campo Grande, MS, Brazil. In order to select participants, we chose to use a convenience sample, which means subjects of both sexes, aged over 12 years old and in regular training practice for at least 12 months. At the moment of start of the present study, the population of Brazilian jiu-jitsu fighters from Campo Grande, MS, Brazil, was constituted by 345 athletes. In order to determine the minimum size sample to the development of the investigation, the measure for prevalence of injured subjects was considered to be $50 \%$. Based on this, and take into account a level of significance of $5 \%$, as well as population dimension, minimum sample size totalized 183 subjects. The studied sample was composed of 193 subjects from 13 Brazilian jiu-jitsu training sites in Campo Grande, MS, Brazil.

\section{Anthropometric characterization and design of groups}

Participants were instructed to wear minimum clothes for all assessments. They were also instructed to refrain from exercise on the day of the tests. Height and body weight measures were obtained, according to the proceedings of previous studies $[14,15]$. Subjects constituted different levels and categories, were $24.5 \pm$ 9.1 years old, and presented $74.4 \pm 19.0 \mathrm{~kg}$ of body weight, $170.0 \pm 10.0 \mathrm{~cm}$ of height, and $37.0 \pm 41.1$ months of regular practice of Brazilian jiu-jitsu.

The study design involved subjects being distributed into three age groups [16]: Adolescents, with adolescents practitioners aged over 12 up until 17 years old; Adults, constituted by adult subjects, aged between 18 and 30 years old; Masters, integrated by master subjects, aged over 30 years old.

\section{Sports injuries and physical activity analyses}

The participants were interviewed and evaluated only once to obtain information about history of practice, level of physical activity, and musculoskeletal injury occurrence due to Brazilian jiu-jitsu practice. The International Physical Activity Questionnaire - Short Form (IPAQ-SF) was used to determine the total physical activity of each participant. Taking into account the score of physical activity, subjects were classified into sedentary, insufficiently active, active, and very active [17].

In order to obtain information about retrospective sports injuries derived from Brazilian jiu-jitsu practice, we used an adapted morbidity survey [18]. The present device was adjusted from previous purposes $[14,15]$ and integrated information about injury occurrence, besides nature, etiological mechanisms, anatomical location, and severity. Sport injury was defined as any symptomatic manifestation of pain or physical dysfunction, due to training practice or Brazilian jiu-jitsu competitions, resulting in training alterations, whether in form, duration, intensity or frequency [19], and integrated cases with onset until 4 years of regular practice of Brazilian jiu-jitsu training. All administering of surveys/ questionnaires and recording of information were performed by two trained researchers. This began with explanations on the objectives and development of the study, followed by implementation of the survey and recording of the notes on the survey.

Afterwards, clinical tests were conducted to analyze the global and segmental joint flexibility, lumbar spine range of motion, and handgrip strength. 


\section{Clinical test}

To analyze global joint flexibility, we considered methodological principles described by Kendall et al. [20]. The posterior static muscle chain is constituted by diverse muscles from paravertebral, lumbar, gluteus, and posterior leg regions. In order to investigate the global alignment of the posterior static muscle chain, each participant stood on a ramp with $30^{\circ}$ tilt, maintaining $60^{\circ}$ of range of flexion to hip and knee joints (Posture 1; Fig. 1). Altered global flexibility of this muscle chain was considered from occurrence of accentuated lumbar lordosis, horizontal pelvis inclination, reduced range of knee flexion, or cavovarus feet [20].

The anterior static muscle chain, which is composed of scalene, psoas, intercostal, diaphragm, and anterior leg muscles, was also assessed and each participant was required to maintain a sitting position on a bed with the legs extended (Posture 2; Fig. 2). Retraction of the anterior static muscle chain was confirmed from anterior positioning of the head and/or occurrence of pelvic retroversion [20]. Posture images were obtained using a photographic chamber (Sony, model DSC-TF1, Brazil), one plumb line, and cutaneous markers [21]. Images underwent independent assessment by three examiners.

The mobility of back and flexibility of leg muscles were analyzed with the use of the sit-and-reach test (Wells and Dillon's Bench) [22]. The subjects sat with their feet approximately hip-wide against the testing box. They kept their knees extended and placed the right hand over the left, and slowly reached forward as far as they could by sliding their hands along the measuring

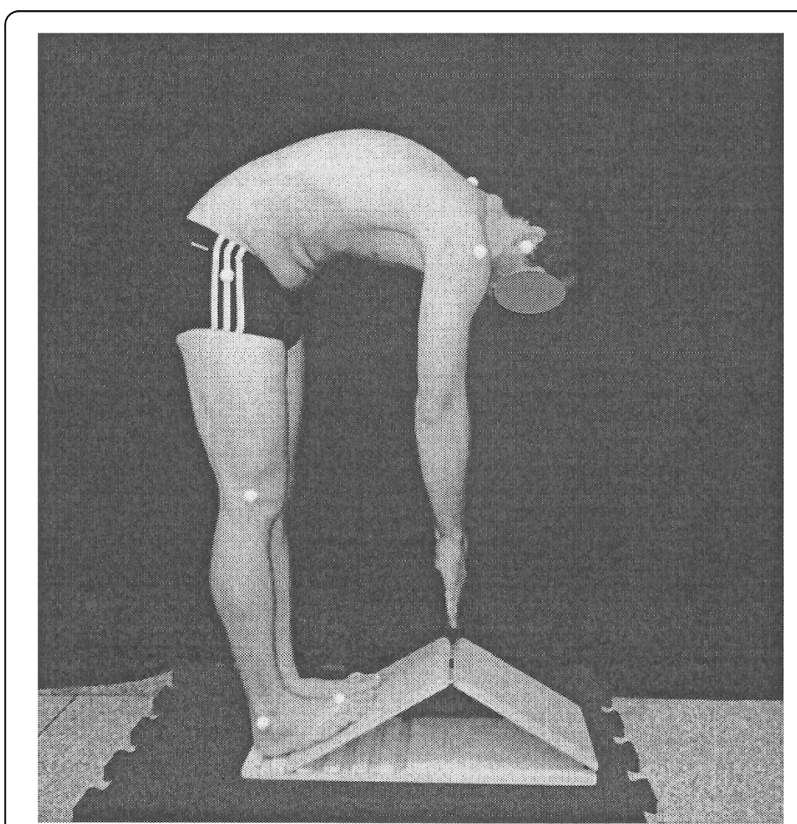

Fig. 1 Posture 1; analysis of global alignment of the posterior static muscle chain

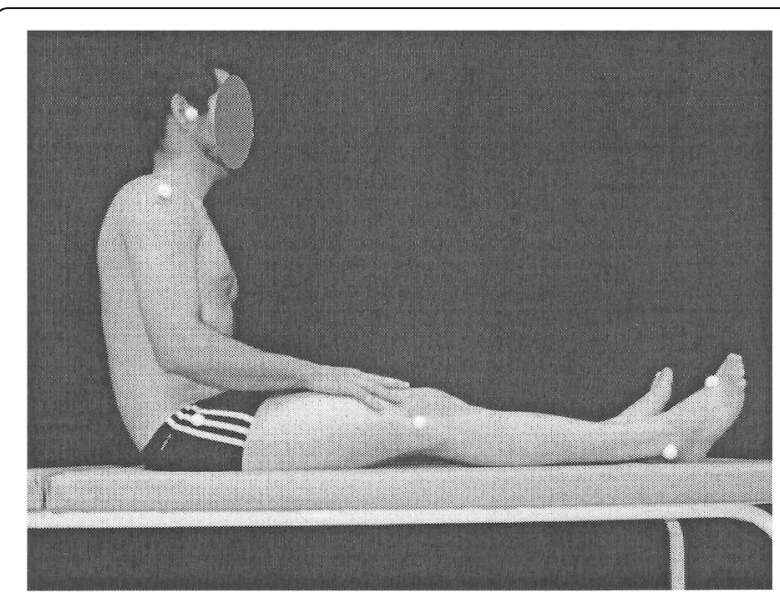

Fig. 2 Posture 2; analysis of global alignment of the anterior static muscle chain

board. For the present assessment, the test was conducted three times with an interval of 30 to $40 \mathrm{~s}$ between tests [22, 23].

The Modified Schober's Test was carried out to investigate the lumbar spine range of motion, according to proceedings previously published [24]. A mark was placed $5 \mathrm{~cm}$ below and $10 \mathrm{~cm}$ above the lumbosacral junction. The participant was asked to bend forward as far as possible and the stretched distance of these two points was measured as the result of the test.

The Thomas test was used to assess bilateral rectus femoris muscle flexibility in each participant [25]; for this, a fleximeter (Code ${ }^{\oplus}$, Brazil) was attached to tibia midpoint. The subject was placed in a supine position with the knees bent over the edge of the examination table, and was instructed to flex one knee to the chest and hold it. At the same time, the angle of the test knee (opposite of the knee held to the chest) was to remain at $90^{\circ}$, and the hip and posterior thigh of the test leg was to remain in a stationary position and regular against the examination table. The muscle flexibility was scored as normal if the tested knee remained in a stationary $90^{\circ}$ position. Differentially, the presence of muscle retraction was confirmed if the test knee extended and moved to a position higher than $90^{\circ}$. Both legs were assessed.

Maximal isometric handgrip strength was recorded using a handheld handgrip dynamometer (Saehan ${ }^{\oplus}$, Smedley-Type, Korea), according to the guidelines of the American Society of Hand Therapists [26]. The device measures strength in kilograms, with a precision of $0.1 \mathrm{~kg}$. Participants were instructed to sit in a straightbacked chair with feet placed flat on the floor, shoulder adducted and neutrally rotated, elbow flexed at $90^{\circ}$, and the forearm and wrist in neutral position. Grip strength was measured 3 times, and the rest between measurements was $15 \mathrm{~s}$. The participants were instructed to 
apply maximal power for $3 \mathrm{~s}$ and work at maximal effort in every trial; maximal value of handgrip strength obtained among the three repetitions was considered as result [26]. An allometric scaling of grip strength by body weight was adopted to obtain results [27].

\section{Statistical analysis}

Demographic and anthropometric variables, history and training period, back mobility, and maximal isometric handgrip strength results were analyzed by One-Way ANOVA. When significant differences were found $(p<0.05)$, the post hoc Student-Newman-Keuls' multiple comparisons test for parametric or Dunn's test for non-parametric distributions were performed. Regarding the qualitative variables, sports injuries results, muscle retraction occurrence, and categories of physical activity were analyzed using Goodman's test for contrasts between and within multinomial populations. Moreover, categorical and continuous data were analyzed using binary logistic regression in software Systat 13 (SYSTAT, Chicago, Illinois). For all internal characteristics, odds ratios (OR) and 95\% confidence intervals (CI) were calculated, and level of significance was considered to be $5 \%$.

\section{Results}

With respect to the constitution of the age groups, all groups have showed a greater proportion of male in relation to female subjects (Table 1); Masters integrated higher proportion of male subjects, in comparison to the Adolescents. Relative to graduation, Adolescents presented greater frequency of white belt rank when compared to Adults and Masters; adults and master categories exhibited similar proportions of intermediate and black belt ranks (Table 1).

Additionally, other characteristics and musculoskeletal injury occurrence are presented in Table 2. Adults and Masters groups showed increased measures of body weight, height, time of practice, and maximal isometric handgrip strength compared to the Adolescents; moreover, Masters presented higher values of body weight, time of practice, and maximal isometric handgrip strength than Adults. In addition, mobility of back and flexibility of leg muscles, analyzed by the sit-andreach test, were similar among age groups $(p=0.08)$. When only subjects with one or more occurrences of sports injuries were considered, Master participants presented lower results from sit-and-reach test in comparison to the Brazilian jiu-jitsu adolescent practitioners (Adolescents $25.80 \pm 7.24$, Adults $26.66 \pm 8.71$, Masters $23.72 \pm 7.75 \mathrm{~cm} ; p=0.004)$. Concerning sports injury occurrence, 247 cases of injuries were registered, resulting in 1.27 case/ subject. Among age groups, $108(43.72 \%)$ cases of injury were reported by Adults; however, the indexes of injury occurrence were increased in Masters, followed by Adults, and Adolescents (Table 2).

Results of muscle flexibility, lumbar spine range of motion, and physical activity levels are presented in Table 3. Concerning the segmental muscle flexibility, the prevalence of rectus femoris muscle retraction in the right leg was increased within Masters. Moreover, the proportion of cases with normal lumbar spine range of motion was higher than the prevalence of cases with reduced lumbar movement in all age groups. Regarding global alignment of the posterior static muscle chain, Adult subjects presented a higher proportion of muscle retraction than Adolescent practitioners. The anterior static muscle chain (Posture 2) as well as physical activity levels were unaffected by the age category; the proportion of subjects with normal alignment of the anterior static muscle chain and very active status for physical activity were amplified within all groups (Table 3).

Epidemiological characterization of sports injuries in terms of nature (type), anatomical localization, and etiological mechanisms is presented in Table 4. Generally, Adults and Masters have exhibited higher occurrence of sports injuries than Adolescents group $(p<0.05)$. Concerning the type, joint hurts have integrated the most common sports-related injuries among Brazilian jiu-jitsu practitioners, which may be confirmed within all age groups. On the other hand, reports of muscle and

Table 1 Constitution of the age groups according gender and graduation

\begin{tabular}{|c|c|c|c|c|}
\hline \multirow[t]{2}{*}{ Variables } & & \multicolumn{3}{|l|}{ Groups } \\
\hline & & G1 (Adolescents) & G2 (Adults) & G3 (Master) \\
\hline \multirow[t]{2}{*}{ Gender } & Female & $16(26.2 \%)^{\mathrm{Ba}}$ & $14(17.7 \%)^{\mathrm{ABa}}$ & $5(9.4 \%)^{\mathrm{Aa}}$ \\
\hline & Male & $45(73.8 \%)^{\mathrm{Ab}}$ & $65(82.3 \%)^{A B b}$ & $48(90.6 \%)^{\mathrm{Bb}}$ \\
\hline \multirow[t]{3}{*}{ Belt rank (Graduation) } & White & $52(85.2 \%)^{B C}$ & $38(48.1 \%)^{\mathrm{Ab}}$ & $16(30.2 \%)^{\mathrm{Ab}}$ \\
\hline & Other & $9(14.8 \%)^{\mathrm{Ab}}$ & $39(49.4 \%)^{\mathrm{Bb}}$ & $29(54.7 \%)^{\mathrm{Bab}}$ \\
\hline & Black & $0(0.0 \%)^{\mathrm{Aa}}$ & $2(2.5 \%)^{\mathrm{ABa}}$ & $8(15.1 \%)^{\mathrm{Ba}}$ \\
\hline Participants (n) & & 61 & 79 & 53 \\
\hline
\end{tabular}

${ }_{\mathrm{A}, \mathrm{B}} p<0.05$ to horizontal comparisons, between different groups; ${ }^{\mathrm{a}}{ }^{\mathrm{b}}, \mathrm{c} p<0.05$ to vertical comparisons, within group. Goodman's test for contrasts between and within multinomial populations 
Table 2 General characteristics and occurrence of musculoskeletal injuries in Brazilian jiu-jitsu practitioners

\begin{tabular}{llll}
\hline Variables & Groups & & \\
\cline { 2 - 4 } & G1 (Adolescents) & G2 (Adults) & G3 (Master) \\
\hline Age (years) & $15.0(12.0-15.0)$ & $25.0(22.0-27.0)^{*}$ & $35.0(32.8-38.0)^{*}$, \# \\
Height (cm) & $1.64 \pm 0.11$ & $1.74 \pm 0.08^{*}$ & $1.75 \pm 0.07^{*}$ \\
Body weight (kg) & $58.1 \pm 13.6$ & $76.6 \pm 12.9^{*}$ & $89.9 \pm 17.4^{*}$, \# \\
TP (months) & $12.0(12.0-13.0)$ & $24.0(12.0-48.0)^{*}$ & $36.0(12.0-99.0)^{*}$, \# \\
Exposure time (h) & $8.00(4.38-12.00)$ & $5.00(4.00-8.00)^{*}$ & $5.00(4.00-7.30)^{*}$ \\
Sit-and-reach test (cm) & $26.4 \pm 6.5$ & $26.5 \pm 9.0$ & $23.7 \pm 7.8$ \\
Hand-grip strenght (kgf) & $27.5 \pm 11.1$ & $38.3 \pm 11.3^{*}$ & $45.8 \pm 11.0^{*}, \#$ \\
Injuries/ Practitioner & 0.59 & 1.37 & 1.94 \\
Injuries/ I. Practitioner & 1.24 & 1.74 & 2.19 \\
Injuries (cases) & 36 & 108 & 103
\end{tabular}

TP time of practice, Flexibility flexibility of back and leg muscles, Hand-grip strenght maximal isometric handgrip strenght, Injuries/l. Practitioner injury incidence per injured practitioner. Height, body weight, flexibility, and hand-grip strenght results are expressed in mean \pm standard deviation, ANOVA and Student-Newman-Keuls test. Age, time of practice, and exposure time results are presented in median and interval between 25 th and 75 th percentile, ANOVA and Dunn test; ${ }^{*} p<0.05$ vs. G1; $\# p<0.05$ vs. G2

joint injuries were proportionally similar within Adults and Masters, and muscle and tendon injuries have been more numerous in Masters compared to Adolescents $(p<0.05)$.

Concerning location, upper and lower limbs constituted the main anatomical sites for onset of sports injuries in Brazilian jiu-jitsu, as sustained by all age groups. Moreover, circumstances of tumbling/ trauma were the most frequent etiological mechanisms for sports injuries occurrence among Adolescent practitioners, while sweep was more commonly referred as the etiological agent for injuries in Adult and Master practitioners. Within group, takedown/ attack situations were as related as sweep in the etiology of sports injuries among adult subjects. Takedown/ attack, sweep, tumbling/trauma, and physical training activities

Table 3 Muscle retractions, lumbar spine range of motion, and physical activity classification

\begin{tabular}{|c|c|c|c|c|c|c|}
\hline \multirow[t]{2}{*}{ Variables } & \multirow[t]{2}{*}{ Responses } & & \multicolumn{3}{|l|}{ Groups } & \multirow[t]{2}{*}{ Total } \\
\hline & & & $\overline{\mathrm{G} 1}$ & G2 & G3 & \\
\hline \multirow[t]{4}{*}{ Right Leg } & \multirow[t]{2}{*}{ MHF } & Absent (-) & $32(52.5)^{\mathrm{Aa}}$ & $39(53.4)^{\mathrm{Aa}}$ & $28(47.5)^{\mathrm{Aa}}$ & 99 \\
\hline & & Present (+) & $29(47.5)^{\mathrm{Aa}}$ & $34(46.6)^{\mathrm{Aa}}$ & $31(52.5)^{\mathrm{Aa}}$ & 94 \\
\hline & \multirow[t]{2}{*}{ RF } & Absent (-) & $35(57.4)^{\mathrm{Aa}}$ & $31(42.5)^{\mathrm{Aa}}$ & $22(37.3)^{\mathrm{Aa}}$ & 88 \\
\hline & & Present (+) & $26(42.6)^{\mathrm{Aa}}$ & $42(57.5)^{\mathrm{Aa}}$ & $37(62.7)^{\mathrm{Ab}}$ & 105 \\
\hline \multirow[t]{4}{*}{ Left Leg } & \multirow[t]{2}{*}{ MHF } & Absent (-) & $33(54.1)^{\mathrm{Aa}}$ & $36(49.3)^{\mathrm{Aa}}$ & $26(44.1)^{\mathrm{Aa}}$ & 95 \\
\hline & & Present (+) & $28(45.9)^{\mathrm{Aa}}$ & $37(50.7)^{\mathrm{Aa}}$ & $33(55.9)^{\mathrm{Aa}}$ & 98 \\
\hline & \multirow[t]{2}{*}{ RF } & Absent (-) & $32(52.5)^{\mathrm{Aa}}$ & $35(47.9)^{\mathrm{Aa}}$ & $28(47.5)^{\mathrm{Aa}}$ & 95 \\
\hline & & Present (+) & $29(47.5)^{\mathrm{Aa}}$ & $38(52.1)^{\mathrm{Aa}}$ & $31(52.5)^{\mathrm{Aa}}$ & 98 \\
\hline \multirow[t]{2}{*}{ Schober } & & Absent (-) & $54(88.5)^{\mathrm{Ab}}$ & $63(86.3)^{\mathrm{Ab}}$ & $51(86.4)^{\mathrm{Ab}}$ & 168 \\
\hline & & Present (+) & $7(11.5)^{\mathrm{Aa}}$ & $10(13.7)^{\mathrm{Aa}}$ & $8(13.6)^{\mathrm{Aa}}$ & 25 \\
\hline \multirow[t]{2}{*}{ Posture 1} & & Absent (-) & $30(49.2)^{\mathrm{Ba}}$ & $19(26.0)^{\mathrm{Aa}}$ & $17(28.8)^{\mathrm{ABa}}$ & 66 \\
\hline & & Present (+) & $31(50.8)^{\mathrm{Aa}}$ & $54(74.0)^{\mathrm{Bb}}$ & $42(71.2)^{\mathrm{ABb}}$ & 127 \\
\hline \multirow[t]{2}{*}{ Posture 2} & & Absent (-) & $47(77.0)^{\mathrm{Ab}}$ & $60(82.2)^{\mathrm{Ab}}$ & $49(83.1)^{\mathrm{Ab}}$ & 156 \\
\hline & & Present (+) & $14(23.0)^{\mathrm{Aa}}$ & $13(17.8)^{\mathrm{Aa}}$ & $10(16.9)^{\mathrm{Aa}}$ & 37 \\
\hline \multirow{4}{*}{\multicolumn{2}{|c|}{ Physical activity categories }} & Sedentary & $7(11,5)^{\text {Aab }}$ & $4(5,5)^{\mathrm{Aa}}$ & $0(0,0)^{\mathrm{Aa}}$ & 11 \\
\hline & & Irreg. Active & $1(1,6)^{\mathrm{Aa}}$ & $3(4,1)^{\mathrm{Aa}}$ & $4(6,8)^{\mathrm{Aab}}$ & 8 \\
\hline & & Active & $13(21,3)^{\mathrm{Ab}}$ & $7(9,6)^{\mathrm{Aa}}$ & $13(22,0)^{\mathrm{Ab}}$ & 33 \\
\hline & & Very Active & $40(65,6)^{\mathrm{Ac}}$ & $59(80,8)^{\mathrm{Ab}}$ & $42(71,2)^{\mathrm{Ac}}$ & 141 \\
\hline
\end{tabular}


Table 4 Sports injuries according to nature (type), anatomical location, etiological mechanisms, and age group

\begin{tabular}{|c|c|c|c|c|c|}
\hline \multirow[t]{2}{*}{ Variables } & & \multicolumn{3}{|l|}{ Age group } & \multirow[t]{2}{*}{ Total } \\
\hline & & $\overline{\mathrm{G} 1}$ & $\mathrm{G} 2$ & G3 & \\
\hline \multirow[t]{5}{*}{ Nature (type) } & Muscle & $4(11.1)^{\mathrm{Aa}}$ & $28(25.9)^{\mathrm{ABb}}$ & $40(38.8)^{\mathrm{Bb}}$ & $72(29.0)$ \\
\hline & Joint & $29(80.6)^{\mathrm{Bb}}$ & $73(67.6){ }^{A c}$ & $48(46.6)^{\mathrm{Ab}}$ & $150(61.0)$ \\
\hline & Bone & $3(8.3)^{\mathrm{Aa}}$ & $3(2.7)^{\mathrm{Aa}}$ & $4(3.9)^{\mathrm{Aa}}$ & $10(4.0)$ \\
\hline & Tendon & $\mathrm{O}(0.0)^{\mathrm{Aa}}$ & $4(3.7)^{\mathrm{ABa}}$ & $11(10.7)^{\mathrm{Ba}}$ & $15(6.0)$ \\
\hline & Total & $36(14.6)$ & $108(43.7)$ & $103(41.7)$ & 247 \\
\hline \multirow[t]{5}{*}{ Location } & Head/ Neck & $0(0.0)^{\mathrm{Aa}}$ & $1(0.9)^{\mathrm{Aa}}$ & $5(4.9)^{\mathrm{Aa}}$ & $6(2.4)$ \\
\hline & Trunk & $3(8.3)^{\mathrm{Aa}}$ & $13(12.0)^{\mathrm{Ab}}$ & $15(14.6)^{\mathrm{Aa}}$ & $31(12.6)$ \\
\hline & Upper Limbs & $17(47.2)^{\mathrm{Ab}}$ & $51(47.2)^{A C}$ & $45(43.7)^{\mathrm{Ab}}$ & $113(45.7)$ \\
\hline & Lower Limbs & $16(44.4)^{\mathrm{Ab}}$ & $43(39.8)^{A C}$ & $38(36.9)^{\mathrm{Ab}}$ & $97(39.3)$ \\
\hline & Total & $36(14.6)$ & $108(43.7)$ & $103(41.7)$ & 247 \\
\hline \multirow[t]{7}{*}{ Mechanism } & Choke/ Arm Wrench & $6(16.7)^{\mathrm{Aa}}$ & $18(16.7)^{\mathrm{Aab}}$ & $13(12.6)^{\text {Aab }}$ & $37(15.0)$ \\
\hline & Takedown/ Attack & $5(13.9)^{\mathrm{Aa}}$ & $26(24.1)^{\mathrm{Ab}}$ & $26(25.2)^{\mathrm{Ab}}$ & $57(23.1)$ \\
\hline & Sweep & $1(2.8)^{\mathrm{Aa}}$ & $23(21.3)^{\mathrm{Bb}}$ & $21(20.4)^{\mathrm{Bb}}$ & $45(18.2)$ \\
\hline & Tumbling/ Trauma & $21(58.3)^{\mathrm{Bb}}$ & $17(15.7)^{\mathrm{Aab}}$ & $20(19.4)^{\mathrm{Ab}}$ & $58(23.5)$ \\
\hline & Physical Training & $2(5.6)^{\mathrm{Aa}}$ & 18 (16.7) Aab & $19(18.4)^{A b}$ & 39 (15.8) \\
\hline & Others & $1(2.8)^{\mathrm{Aa}}$ & $6(5.6)^{\mathrm{Aa}}$ & $4(3.9)^{\mathrm{Aa}}$ & $11(4.5)$ \\
\hline & Total & $36(14.6)$ & $108(43.7)$ & $103(41.7)$ & 247 \\
\hline
\end{tabular}

A, B $p<0.05$ to horizontal comparisons, between different groups; ${ }^{a},{ }^{b} p<0.05$ to vertical comparisons, within group. Goodman's test for contrasts between and within multinomial populations

were similarly referred as causative agents of sports injuries within the Master group (Table 4).

Based on responses about nature (type), localization, and etiological mechanisms, Table 5 brings the descriptive distribution of the most common joint sports injuries among Brazilian jiu-jitsu practitioners. Injuries localized at shoulders constituted the most related record among all participants, integrating $44.3 \%$ of the joint responses $(n=50)$. Tumbling/ trauma circumstances were the primary mechanisms for occurrence of shoulder injuries, as supported by all age groups. Additionally, choke/ arm wrench constituted the primary mechanism for onset of elbow hurts in Adolescents and Masters, while takedown/attack was responsible for the most frequent handle/hands injuries in Adults and Masters (Table 5).

In the pathophysiological aspect, and as support to the design of groups, age as well as global flexibility of the posterior static muscle chain constituted the most predictive variables for sports injury onset among Brazilian jiu-jitsu practitioners $(p<0.05)$; the binary logistic regression model revealed a statistical significance in predicting sports injury occurrence $(p<0.001$; Table 6$)$.

Relative to each age group, female gender and exposure time constituted the most predictive variables for sports injury occurrence among Brazilian jiu-jitsu adolescent practitioners $(p<0.05)$; the binary logistic regression model revealed a statistical significance in predicting sports injury occurrence $(p=0.004$; Table 7).
Table 5 Description of joint musculoskeletal injuries according etiological mechanisms, anatomical localization, and age group

\begin{tabular}{|c|c|c|c|c|c|}
\hline \multicolumn{2}{|l|}{ Variables } & \multicolumn{3}{|c|}{ Age group } & \multirow[t]{2}{*}{ Total } \\
\hline Mechanism & Localization & $\overline{G 1}$ & G2 & G3 & \\
\hline \multirow{4}{*}{$\begin{array}{l}\text { Choke/ } \\
\text { Arm Wrench }\end{array}$} & Shoulder & $2(33.3)$ & $5(45.5)$ & $2(25.0)$ & $9(36.0)$ \\
\hline & Elbow & $4(66.7)$ & $4(36.4)$ & $5(62.5)$ & $13(52.0)$ \\
\hline & Wrist/ Hands & $0(0.0)$ & $2(18.2)$ & $1(12.5)$ & $3(12.0)$ \\
\hline & Total & 6 & 11 & 8 & 25 \\
\hline \multirow{4}{*}{$\begin{array}{l}\text { Takedown/ } \\
\text { Attack }\end{array}$} & Shoulder & $0(0.0)$ & $4(19.0)$ & $1(6.7)$ & $5(12.8)$ \\
\hline & Elbow & $2(66.7)$ & $5(23.8)$ & $1(6.7)$ & $8(20.5)$ \\
\hline & Handle/ Hands & $1(33.3)$ & $12(57.1)$ & $13(86.7)$ & $26(66.7)$ \\
\hline & Total & 3 & 21 & 15 & 39 \\
\hline \multirow[t]{4}{*}{ Sweep } & Shoulder & $0(0.0)$ & $4(66.7)$ & $5(83.3)$ & $9(75.0)$ \\
\hline & Elbow & $0(0.0)$ & $2(33.3)$ & $0(0.0)$ & $2(16.7)$ \\
\hline & Handle/ Hands & $0(0.0)$ & $0(0.0)$ & $1(16.7)$ & $1(8.3)$ \\
\hline & Total & 0 & 6 & 6 & 12 \\
\hline \multirow{4}{*}{$\begin{array}{l}\text { Tumbling/ } \\
\text { Trauma }\end{array}$} & Shoulder & $4(50.0)$ & $5(83.3)$ & $7(100.0)$ & $16(76.2)$ \\
\hline & Elbow & $2(25.0)$ & $1(16.7)$ & $0(0.0)$ & $3(14.3)$ \\
\hline & Handle/ Hands & $2(25.0)$ & $0(0.0)$ & $0(0.0)$ & $2(9.5)$ \\
\hline & Total & 8 & 6 & 7 & 21 \\
\hline \multirow{4}{*}{$\begin{array}{l}\text { Physical } \\
\text { Training }\end{array}$} & Shoulder & $0(0.0)$ & $5(71.4)$ & $6(66.7)$ & $11(68.8)$ \\
\hline & Elbow & $0(0.0)$ & $2(28.6)$ & $3(33.3)$ & $5(31.2)$ \\
\hline & Handle/ Hands & $0(0.0)$ & $0(0.0)$ & $0(0.0)$ & $0(0.0)$ \\
\hline & Total & 0 & 7 & 9 & 16 \\
\hline
\end{tabular}


Table 6 Binary regression of injury risk factors in Brazilian jiu-jitsu practitioners

\begin{tabular}{|c|c|c|c|c|c|}
\hline \multirow{2}{*}{$\begin{array}{l}\text { Variable } \\
\text { Constant }\end{array}$} & \multirow{2}{*}{$\begin{array}{l}\text { Coefficient } \\
-1.548\end{array}$} & \multirow{2}{*}{$\begin{array}{l}\text { OR } \\
-\end{array}$} & \multicolumn{2}{|c|}{$\begin{array}{l}\text { Border values } \\
\text { Cl (95\%) }\end{array}$} & \multirow{2}{*}{$\begin{array}{c}p \text {-value } \\
0.733\end{array}$} \\
\hline & & & - & - & \\
\hline Age & -0.078 & 0.925 & 0.865 & 0.990 & $0.024^{*}$ \\
\hline Female sex & 0.463 & 1.588 & 0.520 & 4.848 & 0.416 \\
\hline Height & 3.014 & 20.368 & 0.154 & 2685.514 & 0.226 \\
\hline Body weight & -0.017 & 0.984 & 0.957 & 1.011 & 0.233 \\
\hline Time of practice & 0.005 & 1.005 & 0.992 & 1.018 & 0.471 \\
\hline Exposure time & -0.041 & 0.960 & 0.876 & 1.052 & 0.381 \\
\hline RF, Left leg & 0.003 & 1.003 & 0.958 & 1.051 & 0.883 \\
\hline RF, Right leg & -0.014 & 0.986 & 0.941 & 1.033 & 0.557 \\
\hline $\begin{array}{l}\text { Hand-grip-strength, } \\
\text { Dhg }\end{array}$ & -0.004 & 0.996 & 0.986 & 1.006 & 0.430 \\
\hline $\begin{array}{l}\text { Hand-grip-strength, } \\
\text { NDhg }\end{array}$ & 0.002 & 1.002 & 0.992 & 1.013 & 0.647 \\
\hline Sit-and-reach test & 0.010 & 1.010 & 0.961 & 1.062 & 0.703 \\
\hline Posture 1 & 1.189 & 3.283 & 1.452 & 7.421 & $0.004^{*}$ \\
\hline Posture 2 & -0.537 & 0.584 & 0.214 & 1.593 & 0.294 \\
\hline Physical activity & -0.294 & 0.745 & 0.461 & 1.204 & 0.230 \\
\hline Graduation & -0.233 & 0.792 & 0.625 & 1.005 & 0.055 \\
\hline Schober & 0.022 & 1.022 & 0.912 & 1.146 & 0.706 \\
\hline
\end{tabular}

$O R$ odds ratio, $R F$ rectus femoris muscle flexibility, Hand-grip-strength, Dhg dominant hand-grip-strength, Hand-grip-strength, NDhg non-dominant hand-grip-strength, Flexibility: flexibility of back and leg muscles; $p<0.05$

Among adults, graduation level was more associated with sports injury occurrence $(p=0.031)$; the binary logistic regression model showed a statistical significance in predicting sports injury occurrence $(p<0.001$; Table 8).

Differentially, a binary logistic regression model destined to present association between risk factors and sports injury occurrence in master subjects did not show statistical significance $(p=0.06$; Table 9$)$.

\section{Discussion}

As main results of the present study, the Masters group showed a higher occurrence of injuries as well as musculoskeletal changes than other age groups. In general, age and global flexibility constituted the more directly associated factors with sports injuries onset in the present casuistry. Notably, other factors have been evidenced as predictive factors for sports injuries within each age group, including sex and exposure time for adolescents, and graduation for adults practitioners of Brazilian jiu-jitsu.

The occurrence of sports injuries and their associations with internal and external characteristics in Brazilian jiu-jitsu subjects are poorly studied, and current investigations have not described the profile of these factors $[28,29]$. In the present study, Masters
Table 7 Binary regression of injury risk factors in Brazilian jiu-jitsu adolescent practitioners

\begin{tabular}{|c|c|c|c|c|c|}
\hline \multirow{2}{*}{$\begin{array}{l}\text { Variable } \\
\text { Constant }\end{array}$} & \multirow{2}{*}{$\begin{array}{l}\text { Coefficient } \\
-2.171\end{array}$} & \multirow{2}{*}{$\begin{array}{l}\text { OR } \\
-\end{array}$} & \multicolumn{2}{|c|}{$\begin{array}{l}\text { Border values } \\
\text { Cl (95\%) }\end{array}$} & \multirow{2}{*}{$\begin{array}{c}p \text {-value } \\
0.858\end{array}$} \\
\hline & & & - & - & \\
\hline Age & -0.46 & 0.628 & 0.272 & 1.445 & 0.274 \\
\hline Female sex & 5.34 & 209.34 & 2.014 & 21,759 & $0.024^{*}$ \\
\hline Height & 8.995 & 8066 & 0.007 & 8.94 & 0.205 \\
\hline Body weight & 0.044 & 1.045 & 0.949 & 1.152 & 0.371 \\
\hline Time of practice & -0.018 & 0.982 & 0.877 & 1.099 & 0.750 \\
\hline Exposure time & -0.363 & 0.696 & 0.504 & 0.961 & $0.028^{*}$ \\
\hline RF, Left leg & -0.001 & 0.999 & 0.906 & 1.102 & 0.990 \\
\hline RF, Right leg & 0.031 & 1.032 & 0.906 & 1.174 & 0.638 \\
\hline Hand-grip-strength, Dhg & 0.004 & 1.004 & 0.973 & 1.036 & 0.802 \\
\hline Hand-grip-strength, NDhg & -0.016 & 0.984 & 0.948 & 1.021 & 0.395 \\
\hline Sit-and-reach test & -0.186 & 0.830 & 0.601 & 1.145 & 0.257 \\
\hline Posture 1 & -0.335 & 0.716 & 0.004 & 138.971 & 0.901 \\
\hline Posture2 & 1.327 & 3.770 & 0.007 & 24.550 & 0.273 \\
\hline Physical activity & 2.218 & 9.191 & 0.594 & 142.339 & 0.113 \\
\hline Graduation & -0.697 & 0.498 & 0.194 & 1.282 & 0.148 \\
\hline Schober & -0.234 & 0.792 & 0.522 & 1.202 & 0.273 \\
\hline
\end{tabular}

$O R$ odds ratio, $R F$ rectus femoris muscle flexibility, Hand-grip-strength, Dhg dominant hand-grip-strength, Hand-grip-strength, NDhg, non-dominant hand-grip-strength; ${ }^{*} p<0.05$

Table 8 Binary regression of injury risk factors in Brazilian jiu-jitsu adult practitioners

\begin{tabular}{llllll}
\hline Variable & Coefficient & OR & \multicolumn{3}{l}{$\begin{array}{l}\text { Border values } \\
\text { Cl (95\%) }\end{array}$} \\
\hline Constant & -9.459 & - & - & - & 0.761 \\
Age & -0.075 & 0.928 & 0.621 & 1.386 & 0.716 \\
Female sex & -1.433 & 0.239 & 0.001 & 56.166 & 0.607 \\
Height & 13.156 & 516.869 & 0.000 & 8.491 & 0.318 \\
Body weight & -0.094 & 0.910 & 0.811 & 1.022 & 0.111 \\
Time of practice & -0.076 & 0.927 & 0.848 & 1.014 & 0.099 \\
Exposure time & -0.015 & 0.985 & 0.696 & 1.396 & 0.934 \\
RF, Left leg & 0.082 & 1.085 & 0.941 & 1.252 & 0.262 \\
RF, Right leg & -0.105 & 0.900 & 0.783 & 1.036 & 0.141 \\
Hand-grip-strength, Dhg & -0.023 & 0.977 & 0.943 & 1.012 & 0.195 \\
Hand-grip-strength, NDhg & 0.027 & 1.027 & 0.986 & 1.070 & 0.204 \\
Sit-and-Reach test & 0.031 & 1.032 & 0.902 & 1.179 & 0.649 \\
Posture 1 & 1.353 & 3.869 & 0.377 & 39.718 & 0.255 \\
Posture2 & 0.256 & 1.292 & 0.053 & 31.265 & 0.875 \\
Physical activity & -0.796 & 0.451 & 0.108 & 1.877 & 0.274 \\
Graduation & -2.152 & 0.116 & 0.016 & 0.824 & $0.031^{*}$ \\
Schober & -0.023 & 0.977 & 0.543 & 1.758 & 0.939 \\
\hline OR odds rato, & & & &
\end{tabular}

$O R$ odds ratio, $R F$ rectus femoris muscle flexibility, Hand-grip-strength, Dhg dominant hand-grip-strength, Hand-grip-strength, NDhg non-dominant hand-grip-strength; ${ }^{*} p<0.05$ 
Table 9 Binary regression of injury risk factors in Brazilian jiu-jitsu master practitioners

\begin{tabular}{llllll}
\hline Variable & Coefficient & OR & \multicolumn{3}{l}{$\begin{array}{l}\text { Border values } \\
\text { Cl (95\%) }\end{array}$} \\
\hline Constant & -13.067 & - & - & - & 0.545 \\
Age & -0.165 & 0.848 & 0.582 & 1.236 & 0.391 \\
Female sex & 4.593 & 98.797 & 0.191 & $51,068.442$ & 0.150 \\
Height & 3.134 & 22.954 & 0.000 & 8.628 & 0.756 \\
Body weight & -0.056 & 0.945 & 0.833 & 1.073 & 0.382 \\
Time of practice & 0.039 & 1.040 & 0.995 & 1.087 & 0.085 \\
Exposure time & 0.168 & 1.183 & 0.749 & 1.870 & 0.471 \\
RF, Left leg & 0.190 & 1.209 & 0.962 & 1.519 & 0.103 \\
RF, Right leg & -0.091 & 0.913 & 0.729 & 1.144 & 0.430 \\
Hand-grip-strength, & -0.004 & 0.996 & 0.967 & 1.026 & 0.792 \\
Dhg & & & & & \\
Hand-grip-strength, & -0.005 & 0.995 & 0.966 & 1.025 & 0.744 \\
NDhg & & & & & \\
Sit-and-Reach test & 0.171 & 1.186 & 0.920 & 1.531 & 0.189 \\
Posture 1 & 3.417 & 30.464 & 0.715 & 1298.46 & 0.074 \\
Posture2 & -5.184 & 0.006 & 0.000 & 0.797 & $0.040^{*}$ \\
Physical activity & -2.617 & 0.073 & 0.000 & 16.477 & 0.344 \\
Graduation & -0.336 & 0.714 & 0.171 & 2.980 & 0.644 \\
Schober & 0.438 & 1.550 & 0.772 & 3.115 & 0.218 \\
\hline OR odds rato, & & & &
\end{tabular}

$O R$ odds ratio, $R F$ rectus femoris muscle flexibility, Hand-grip-strength, Dhg dominant hand-grip-strength, Hand-grip-strength, NDhg non-dominant hand-grip-strength; $p<0.05$

group showed a higher occurrence of injuries as well as musculoskeletal changes than other age groups. Also, it is probable that different indexes of sports injuries occurrence among age groups (Table 2) have been associated with multifactorial clinical aspects, including anthropometrical features and time of practice. Anthropometrical differences may result from dietary conduct combined with age development and training practice [30]. Other possible internal characteristics were investigated, such as muscle flexibility, back mobility, physical activity level and maximal isometric handgrip strength. However, potential associations between these diverse factors and sports injury onset were not detected in master subjects (Table 9).

Concerning the physical activity level, this variable is commonly used in studies for specific population groups [17]. To verify whether regular physical activity affects training performance, IPAQ has been administered in studies on sports sciences. In general, Brazilian jiu-jitsu constitutes the primary sporting modality of the participants of the present study. According to IPAQ results, high intensities of training are commonly used to improve athletic performance in Brazilian jiu-jitsu, impacting on physical activity levels. Concerning muscle strength, measures of maximal isometric handgrip strength are affected by age and sex, since increased age values have been associated with higher strength responses, despite possible normalizations by other variables, such as body weight [27]. The results presented confirmed this supposition (Tables 1 and 2).

Flexibility and adequate joint mobility are very common characteristics among practitioners subjects of Brazilian jiu-jitsu, since training practice and combat circumstances are accompanied by activities of muscle stretching [31]. Therefore, adequate back mobility and muscle flexibility may result from sports practice of Brazilian jiu-jitsu (Table 3). Regression analysis sustained that disturbed flexibility of the posterior muscle chain $(\mathrm{OR}=1.189 ; p=0.004)$ is associated with sports injury occurrence in Brazilian jiu-jitsu practitioners. Importantly, Master subjects showed increased prevalence of sports injuries and muscle retraction in global context (Tables 2, 3, 4).

Practice of combat modalities is characterized by important biomechanical requirements for lower limbs in order to ensure static and dynamic motor control during fights $[1,2,4]$. As a result, increased and specific musculoskeletal demands can be established, with potential possibilities for development of muscle retractions and posture alterations. Since muscle flexibility is also affected by age [12], Brazilian jiu-jitsu demands along with age-induced effects may explain the lower posterior muscle chain flexibility in adult and Master participants.

Intriguingly, results evidenced that the Adolescents has presented higher weekly time exposure of training than the other age groups (Table 2). Besides exposure time, female sex has also emerged as the most directly associated internal factors for sports injury occurrence in Adolescents, although this group has revealed higher proportion of female participants (Table 1). In order to increase possibilities of sport success in the adult phase, sports training schedules for infant and adolescent practitioners have tried to hasten improvements in physical and technical performance [32]. However, inadequate training planning can promote excessive time of exposure and physical overload, which can impair motor development, with potential risks for sports injury occurrence in Adolescent subjects [32, 33]. Despite the increased weekly training, it's possible that Adolescents group has showed impaired physical and technical performance, since tumbling/ trauma constituted the main etiological circumstance for onset of sports injuries in Adolescent practitioners (Table 4). These mechanisms are the main and most common conditions associated with different situations of attack and defense during Brazilian jiu-jitsu practice [2-4]. Also, shoulders constituted the most frequently injured anatomical site, and tumbling/ trauma were the main etiological circumstances for this (Table 5). 
Moreover, female sex constituted another predictive factor for the occurrence of sports injuries in adolescent practitioners. Authors postulated that the female-athlete triad is the main factor responsible for the increased female susceptibility to sports injuries in comparison to male subjects [10]. This condition is characterized by increased physical fatigue associated with nutritional disorders, menstrual disturbances, and lower bone density. Other characteristics, such as anthropometrical measures and musculoskeletal development, have also been identified as responsible for the higher female susceptibility to sports injuries $[12,13]$. Therefore, the combination between female sex and high exposure time to training has been sustaining a probable predictive mechanism for sports injury occurrence among adolescent practitioners of Brazilian jiu-jitsu.

In general, physical and technical improvements in response to Brazilian jiu-jitsu training have been accompanied by important sport competitiveness and progressive overload $[1-5,8]$. On the other hand, Brazilian jiu-jitsu practice is not scheduled according to a training periodization, as observed in other competitive sports. Consequently, adult and master athletes have commonly been submitted to the high intensity of training activities not interspersed by adequate recovery periods. Accordingly, combat demands, i.e. sweep, were the most related mechanisms for occurrence of injuries by Adults and Masters. The high competitiveness of adult and master subjects has also been sustained by the great number of injuries in handle/hands sites derived from takedown/attack circumstances (Table 5). Some authors reported joint soreness or injury in upper limbs and knees as the most prevalent musculoskeletal injuries in Brazilian jiu-jitsu [34]. Actually, joint injuries at upper and lower limbs were the most common injuries in all age groups (Table 4).

Additionally, graduation by category constituted the most associated factors to sports injury occurrence in adult subjects (Table 8). The predictive potential of the graduation by categories is documented in literature; authors [9] have verified increased prevalence of injuries with the progression of the graduation categories. This increased susceptibility of the graduated subjects may be derived from the high intensity of training and Brazilian jiu-jitsu competitiveness.

Although the present study can contribute to new information to scientific literature concerning the pathophysiology of sport injuries in Brazilian jiu-jitsu practitioners, the etiological role of the studied characteristics must be better analyzed in prospective investigations. Furthermore, other risk factors, such as biomechanical factors, and anthropometrical characteristics, should also be clarified in future studies concerning sports injury occurrence in adolescent, adult, and master Brazilian jiu-jitsu practitioners.

\section{Conclusion}

Joint injuries in the shoulder derived from combat demands were the main sports injuries in all age categories of Brazilian jiu-jitsu. 30-year-old subjects or older presented a higher occurrence of clinical changes and retrospective musculoskeletal injuries in relation to other age groups. Female gender and exposure time constituted the main predictive factors in adolescent practitioners, while graduation category was more directly associated with retrospective injury occurrence in the adult group.

\section{Abbreviations}

Cl: 95\% confidence intervals: FJJD-MS: Federação de Jiu Jitsu Desportivo do Estado de Mato Grosso do Sul, Campo Grande, MS, Brazil; IPAQ-

SF: International Physical Activity Questionnaire - Short Form; One-Way

ANOVA: one way analysis of variance; OR: odds ratios

\section{Acknowledgments}

We are grateful to Mr. Fabio Rocha and volunteers (FJJD-MS), from Campo Grande, MS, for participation in the study, Fundação Manoel de Barros and Daniela Bomfim Rodrigues for English editing.

\section{Funding}

Not applicable

\section{Availability of data and materials}

As the data are drawn from an athletic population; the data and materials will only be made available upon specific request made to the corresponding Author who will seek approval from both the Federations and the relevant Human Research Ethics Committee prior to the provision of any data.

\section{Authors' contributions}

DG: Assisted in obtaining ethical clearances, collected and assisted in data analysis and developed the manuscript. LN and FSSB: collected and assisted in data analysis and developed the manuscript. PFM and FAR: oversaw and finalized data interpretation and edited the manuscript. SAOJ: obtained ethical and clearance approvals, oversaw and finalized data interpretation and edited the manuscript. All authors read and approved the final manuscript.

\section{Ethics approval and consent to participate}

The Ethics Committee of the Federal University of Mato Grosso do Sul (CEP/ UFMS) granted ethics approval for the research (Protocol 575.773/ 2014; CAAE 26804614.7.0000.0021). All participants were given verbal and written information before they agreed to participate and to sign a consent form. Parental or legal guardian consent, written and verbal, was obtained for all participants under the age of 18 years-old.

\section{Consent for publication}

Not applicable

Competing interests

The authors declare that they have no competing interests.

\section{Publisher's Note}

Springer Nature remains neutral with regard to jurisdictional claims in published maps and institutional affiliations.

\section{Author details}

${ }^{1}$ Postgraduate Program in Health and Development, Federal University of Mato Grosso do Sul, Campo Grande, MS, Brazil. ${ }^{2}$ School of Physical Therapy, Federal University of Mato Grosso do Sul, Campo Grande, MS, Brazil. ${ }^{3}$ School of Physical Therapy, Anhanguera University - UNIDERP, Campo Grande, MS, Brazil. ${ }^{4}$ Laboratoty of Striated Muscle Study (LEME/ CEI), Federal University of Mato Grosso do Sul, Campo Grande, MS, Brazil. 
Received: 26 December 2016 Accepted: 15 October 2017

Published online: 23 October 2017

\section{References}

1. Reis FJ, Dias MD, Newlands F, Meziat-Filho N, Macedo AR. Chronic low back pain and disability in Brazilian jiu-jitsu athletes. Phys Ther Sport. 2015;16(4):340-3.

2. da Silva BVC, Ide BN, Simim MAM, Marocolo M, Mota GR. Neuromuscular responses to simulated Brazilian Jiu-Jitsu fights. J Hum Kinet. 2014;44(1): 249-57.

3. Andreato LV, Julio UF, Panissa VL, Esteves JV, Hardt F, de Moraes SM, et al. Brazilian jiu-jitsu simulated competition part I: metabolic, hormonal, cellular damage, and heart rate responses. J Strength Cond Res. 2015;29(9):2538-49.

4. Andreato LV, Julio UF, Gonçalves Panissa VL, Del Conti Esteves JV, Hardt F, Franzói de Moraes SM, et al. Brazilian jiu-jitsu simulated competition part II: physical performance, time-motion, technical-tactical analyses, and perceptual responses. J Strength Cond Res. 2015;29(7):2015-25.

5. da Silva BV, Simim MA, Marocolo M, Franchini E, da Mota GR. Optimal load for the peak power and maximal strength of the upper body in Brazilian Jiu-Jitsu athletes. J Strength Cond Res. 2015;29(6):1616-21.

6. Bahr $R$, Krosshaug T. Understanding injury mechanism: a key component of injury prevention in sport. Brit J Sports Med. 2005;39(6):324-9.

7. Bledsoe GH, Hsu EB, Grabowski JG, Brill JD, Li G. Incidence of injury in professional mixed martial arts competitions. J Sports Sci Med. 2006; 5(CSSI):136-42.

8. Scoggin JF, Brusovanik G, Izuka BH, Zandee van Rilland E, Geling O, Tokumura S. Assessment of injuries during Brazilian Jiu-Jitsu competition. Orthop J Sports Med. 2014;2(2):2325967114522184.

9. Kreiswirth EM, Myer GD, Rauh MJ. Incidence of injury among male Brazilian Jiu-Jitsu fighters at the world Jiu-Jitsu no-Gi championship 2009. J Athl Train. 2014:49(1):89-94

10. Folscher LL, Grant CC, Fletcher L, Rensberg DCJV. Ultra-marathon athletes at risk for the female athlete triad. Sports Med. 2015;1(29):2-8.

11. Vanderlei FM, Bastos FN, Tsutsumi GY, Vanderlei LC, Netto Júnior J, Pastre CM. Characteristics and contributing factors related to sports injuries in young volleyball players. BMC Res Notes. 2013;6:415.

12. Hagglund $M$, Walden M. Risk factors for acute knee injury in female youth football. Knee Surg Sports Traumatol Arthrosc. 2016;24(3):737-46.

13. Kim KS, Park KJ, Lee J, Kang BY. Injuries in national Olympic level judo athletes: an epidemiological study. Brit J Sports Med. 2015;49(1):1-7.

14. Silveira KP, Assunção VHS, Guimarães NP Jr, Barbosa SRM, Santos MLM, Carregaro RL, Oliveira-Júnior SA. Nosographic profile of soccer injuries according to the age group. Rev Bras Cineantropom Desempenho Hum. 2013;15(4):476-85.

15. Schweich LC, Gimelli AM, Elosta MB, Matos WSW, Martinez PF, Oliveira Júnior SA. Epidemiology of athletic injuries in classic ballet practitioners. Fisioter Pesq. 2014;21(4):353-8.

16. International Brazilian Jiu-Jitsu Federation (IBJJF). General system of graduation. Rio de Janeiro: IBJJF; 2012. p. 18.

17. Pardini R, Matsudo S, Araujo T, Matsudo V, Andrade E, Braggion G, et al. Validação do questionário internacional de nível de atividade física (IPAQversão 6): estudo piloto em adultos jovens brasileiros. Rev Bras Cien e Mov. 2001;9(3):45-51.

18. Pastre CM, Carvalho Filho G, Monteiro HL, Neto Junior J, Padovani CR. Lesões desportivas no atletismo: comparação entre informações obtidas em prontuários e inquéritos de morbidade referida. Rev Bras Med Esporte. 2004; 10(1):1-8.

19. Fuller CW, Ekstrand J, Junge A, Andersen TE, Bahr R, Dvorak J, et al. Consensus statement on injury definitions and data collection procedures in studies of football (soccer) injuries. Scand J Med Sci Sports. 2006;16(2):83-92.

20. Kendall FP, McCreary EK, Provance PG, Rodgers MM, Romani WA. Muscles: testing and function with posture and pain (fifth ed.) Lippincott, Williams, \& Wilkins, Baltimore, MD (2005)

21. Neto Junior J, Pastre CM, Monteiro HL. Alterações posturais em atletas brasileiros do sexo masculino que participaram de provas de potência muscular em competições internacionais. Rev Bras Med Esporte. 2004;10(3):195-8.

22. Wells KE, Dillon EK. The sit-and-reach test of back and leg flexibility. Res Quart. 1952;23:115-8

23. López-Miñarro PA, Andújar PSB, Rodríguez-García PL. A comparison of the sit-and-reach test and the back-saver sit-and-reach test in university students. J Sports Sci Med. 2009;8(1):116-22.
24. Macedo CSG, Souza PR, Alves PM, Cardoso JR. Estudo da validade e confiabilidade intra e interobservador da versão modificada do teste de Schöber modificado em indivíduos com lombalgia. Fisioter Pesq. 2009;16(3):233-8.

25. Peeler J, Anderson JE. Reliability of the Thomas test for assessing range of motion about the hip. Phys Ther Sport. 2007:8:14-21.

26. Fess EE. Grip strength. In: Casanova JS, editor. Clinical 22. assessment recommendations. 2nd ed. Chicago: American Society of Hand Therapists; 1992. p. 41-5.

27. Vanderburgh PM, Mahar MT, Chou CH. Allometric scaling of grip strength by body mass in college-age men and women. Res Q Exerc Sport. 1995; 66(1):80-4.

28. Rodrigues MF, Crosato EM, Cardoso JR, Traebert J. Psychometric properties and cross-cultural adaptation of the Brazilian Quebec back pain disability scale questionnaire. Spine. 2009;34(13):459-64.

29. McClain R, Wassermen J, Mayfield C, Berry AC, Grenier G, Suminski RR, et al. Injury profile of mixed martial arts competitors. Clin J Sport Med. 2014;24(6): 497-501.

30. Abidin NZ, Adam MB. Prediction of vertical jump height from anthropometric factors in male and female martial arts athletes. Malays J Med Sci. 2013:20(1):39-45.

31. Oliveira KMS, Filho IS, Santos LBF, Brito CJ. Alongamento estático e facilitação neuromuscular proprioceptiva não afetam o desempenho de força máxima em lutadores de Brazilian jiu-jitsu. Arq Cien Esporte. 2014;1 (1):28-32.

32. Arriaza $R$, Inman $D$, Arriaza A, Saavedra MA. Low risk of injuries in young adolescents participation in top-level karate competition. Am J Sports Med. 2016:44(2):305-8.

33. Noh JW, Park BS, Kim MY, Lee LK, Yang SM, Lee WD, et al. Analysis of combat sports players' injuries according to playing style for sports physiotherapy research. J Phys Ther Sci. 2015;27(8):2425-30.

34 Souza JMC, Faim FT, Nakashima IY, Altruda CR, Medeiros WM, Silva LR. Lesões no Karate Shotokan e no Jiu-Jitsu: trauma direto versus indireto. Rev Bras Med Esporte. 2011;17(2):107-10.

\section{Submit your next manuscript to BioMed Central and we will help you at every step:}

- We accept pre-submission inquiries

- Our selector tool helps you to find the most relevant journal

- We provide round the clock customer support

- Convenient online submission

- Thorough peer review

- Inclusion in PubMed and all major indexing services

- Maximum visibility for your research

Submit your manuscript at www.biomedcentral.com/submit 